\title{
Highly Transparent and Surface-Plasmon-Enhanced Visible-Photodetector Based on Zinc Oxide Thin-Film Transistors with Heterojunction Structure
}

\author{
Cheng-Jyun Wang ${ }^{1}$, Hsin-Chiang You ${ }^{2}$, Kuan Lin ${ }^{1}$, Jen-Hung Ou ${ }^{1}$, Keng-Hsien Chao ${ }^{1}$ and \\ Fu-Hsiang Ko ${ }^{1, *}$ \\ 1 Department of Materials Science and Engineering, National Chiao-Tung University, 1001 University Rd., \\ Hsinchu 30010, Taiwan; cjwang.nano03g@nctu.edu.tw (C.-J.W.); osho8888@gmail.com (K.L.); \\ harveyou@hotmail.com.tw (J.-H.O.); lces32051.nano07g@nctu.edu.tw (K.-H.C.) \\ 2 Department of Electronic Engineering, National Chin-Yi University of Technology, No. 57, Sec. 2, \\ Zhongshan Rd., Taiping Dist., Taichung 41170, Taiwan; hcyou@ncut.edu.tw \\ * Correspondence: fhko@mail.nctu.edu.tw; Tel.: +886-3-5712121
}

Received: 27 September 2019; Accepted: 4 November 2019; Published: 5 November 2019

\begin{abstract}
Highly transparent zinc oxide (ZnO)-based thin-film transistors (TFTs) with gold nanoparticles (AuNPs) capable of detecting visible light were fabricated through spray pyrolysis on a fluorine-doped tin oxide substrate. The spray-deposited channel layer of $\mathrm{ZnO}$ had a thickness of approximately $15 \mathrm{~nm}$, and the thickness exhibited a linear increase with an increasing number of sprays. Furthermore, the $\mathrm{ZnO}$ thin-film exhibited a markedly smoother channel layer with a significantly lower surface roughness of $1.84 \mathrm{~nm}$ when the substrate was $20 \mathrm{~cm}$ from the spray nozzle compared with when it was $10 \mathrm{~cm}$ away. Finally, a $\mathrm{ZnO}$ and Au-NP heterojunction nanohybrid structure using plasmonic energy detection as an electrical signal, constitutes an ideal combination for a visible-light photodetector. The ZnO-based TFTs convert localized surface plasmon energy into an electrical signal, thereby extending the wide band-gap of materials used for photodetectors to achieve visible-light wavelength detection. The photo-transistors demonstrate an elevated on-current with an increase of the AuNP density in the concentration of 1.26, 12.6, and $126 \mathrm{pM}$ and reach values of $3.75,5.18$, and $9.79 \times 10^{-7} \mathrm{~A}$ with applied gate and drain voltages. Moreover, the threshold voltage (Vth) also drifts to negative values as the AuNP density increases.
\end{abstract}

Keywords: zinc oxide-based thin-film transistors; gold-nanoparticles; phototransistors; spray pyrolysis; plasmonic energy detection

\section{Introduction}

Thin-film transistors (TFTs) based on transparent conductive oxide (TCO) materials have attracted increasing attention for their applications in optoelectronic devices and ultraviolet (UV) light detectors in the past few years, due to their advantages including a wide-band gap, suitable optical transparency, simple solution-based manufacturing, and low-temperature processability [1-4]. Solution-based processing of TCO materials, such as zinc oxide $(\mathrm{ZnO}), \mathrm{Ga}_{2} \mathrm{O}_{3}$ and $\mathrm{SnO}_{2}$ have been extensively studied for application in the channel layer and ultraviolet (UV) optical band detecting layer $[5,6]$. $\mathrm{ZnO}$ is a suitable material for use in the production of UV sensitizers and broad band transparent conductors for visible-blind UV detection with the additional advantages of high transparency; for direct band-gap semiconductors with band-gap of $3.37 \mathrm{eV}$ and the solution processability enables high-performance photo-detecting devices to be manufactured simply, at lower-cost, and with large-areas [7-12]. Therefore, TCO materials are considered the most appropriate semiconducting materials because of their transparency, high-performance electrical, and UV light detecting properties. 
These materials have been used a photodetecting layer, which can convert a UV wavelength region into an electrical signal. An intrinsically wide band-gap limits the light absorption of a high-energy UV region. Several methods have been reported to improve the photo-responsivity of TCO-based TFTs in a visible wavelength region, such as the use of quantum dots, and polymeric absorption thin-film layers [12-14]. In particular, the metallic nanoparticles of gold nanoparticles (AuNPs) exhibit distinct surface plasmonic properties because of the abundance of energized electrons on the particle surfaces [15]. The metallic nanoparticles (NPs) of localized surface plasmon resonance (LSPR), which is an efficient conversion of plasmon energy into an electrical signal for an illumination-specific light wavelength, can be employed for visible-light photodetection. The $\mathrm{ZnO}$ and AuNPs heterojunction nanohybrid structure enables plasmonic energy detection as a form of an electrical signal and constitutes an ideal combination of visible light photodetection. Photons absorbed in a metal nanostructure generate hot electrons which can cross by thermionic diffusion at the boundary between metal and a semiconducting layer, thereby generating a photocurrent or modifying the energy band gap in the semiconducting layer of $\mathrm{ZnO}$ [16-19]. Therefore, this phenomenon is promising for the development of a photodetector with TCO-based TFTs and increased visible-light detection wavelengths.

In recent years, solution-based manufacturing technologies have been promising candidates for the manufacturing of next generation materials for sensing electronic devices due to their potential benefits including reduced production costs, large area fabrication, low temperature processing, and suitability for various substrates e.g., flexible and glass substrates [20-25]. Generally, the spin-coating, ink-jet printing, and spray pyrolysis deposition are the prevalently used methods for manufacturing the channel layer of TFTs using solution-based technologies [26-30]. Although a more uniform and ultra-thin film is generated in spin-coating and numerous studies have employed spin coating, it is not a suitable method for large-area manufacturing, particularly for glass substrates and products in the electronic display. Among the various solution-based deposition techniques, spray pyrolysis is unique because it combines the synthetic versatility and large-area manufacturing of solution processing by using favorable growth mechanics, thus generating a film with extraordinary electrical characteristics [31]. Furthermore, this deposition method is used as a scalable technology for depositing TCO materials in numerous applications, including semiconducting industry and solar cells [32-36]. In particularly, this depositing method can spray materials over a large-area on glass substrates.

\section{Materials and Methods}

Figure 1a presents the zinc oxide-based thin-film transistors (ZnO-based TFTs) with gold nanoparticles (AuNPs) structure for extending the range of light absorbed. First, the transparent conducting oxide solution of $\mathrm{ZnO}$ was prepared by dissolving zinc acetate-dihydrate $\left[\mathrm{Zn}\left(\mathrm{CH}_{3} \mathrm{COO}\right)_{2} \cdot 2 \mathrm{H}_{2} \mathrm{O}\right]$ into ethanol $\left(\mathrm{CH}_{3} \mathrm{CH}_{2} \mathrm{OH}\right.$, absolute $\left.\geq 99.8 \%\right)$ as a precursor with a concentration of $0.05 \mathrm{M}$, and the solution was then gently stirred for $1.5 \mathrm{~h}$ at $60{ }^{\circ} \mathrm{C}$ until a highly transparent solution was obtained. The gold-nanoparticle (AuNP) solution was prepared by adding $1 \mathrm{~mL}$ of $38.8 \mathrm{~mL}$ aqueous trisodium citric acid $\left(\mathrm{Na}_{3} \mathrm{C}_{6} \mathrm{H}_{5} \mathrm{O}_{7}, \mathrm{TSC}\right)$ into $1 \mathrm{mM}$ of aqueous boiling solution of hydrogen tetrachloroaurate $\left(\mathrm{HAuCl}_{4}\right)$, and the resulting mixture was continuously boiled for $30 \mathrm{~min}$ until a red solution was obtained. Then, AuNPs with a diameter of $13 \mathrm{~nm}$ were obtained.

For device fabrication, a transparent, conducting fluorine-doped tin oxide (FTO) substrate was treated via a standard clean one (SC-1) cleaning procedure to eliminate organic and particle contamination before depositing an oxide film. Then, a $300 \mathrm{~nm}$ thick layer of silicon nitride oxide $\left(\mathrm{Si}_{3} \mathrm{~N}_{4}\right)$ was deposited on the FTO substrate through the low-temperature processing of a plasma-enhanced chemical vapor deposition (PECVD) system at $300^{\circ} \mathrm{C}$. Before incorporating AuNP nanostructures, electrical characteristics were evaluated for all fabricated the ZnO-based TFT devices. The ability for plasmonic energy detection included incorporating AuNPs in an active channel layer of $\mathrm{ZnO}$, thus fabricating a metal-semiconducting junction structure. The AuNPs were connected with the $\mathrm{ZnO}$ channel layer and silicon nitride oxide by using (3-mercaptopropyl)trimethoxysilane (MPTMS) with concentrations of $1.26,12.6$, and $126 \mathrm{pM}$. Subsequently, the $\mathrm{ZnO}$ precursor solution was then 
spray deposited according to the various spray pyrolysis deposition conditions of different layers, such as the distance between the substrate and spray nozzle and active material used for the n-type semiconducting and photosensitive layer, followed by air annealing at $300{ }^{\circ} \mathrm{C}$ for 1 hour. Finally, the source and drain electrode regions were defined by metal mask followed by a thermal coater deposition of $300 \mathrm{~nm}$ thick aluminum. The thin-film transistors of channel length and width were $70 \mu \mathrm{m}$ and $2000 \mu \mathrm{m}$, respectively, as shown in Figure 1b.

(a)

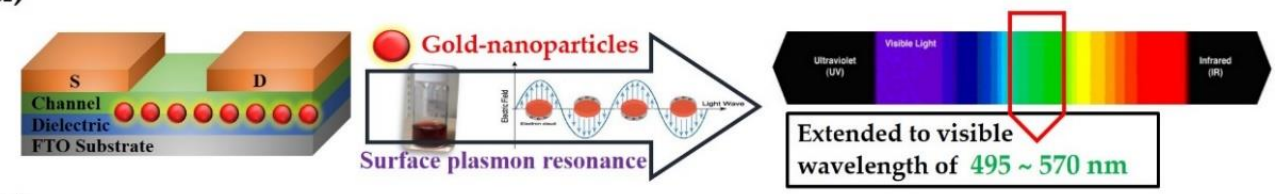

(b)

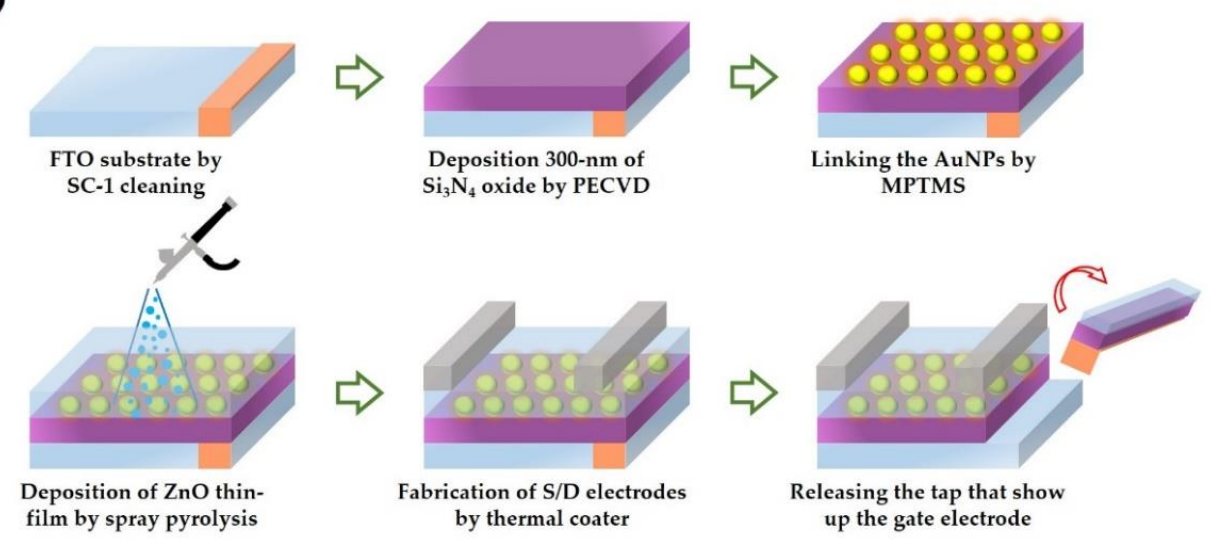

Figure 1. Photodetector with ZnO-based thin-film transistors (TFTs) and gold nanoparticles (AuNPs) fabricated on a transparent fluorine-doped tin oxide (FTO) structure. (a) Schematic and illumination of the photodetector. (b) Fabrication procedure of the photodetector with ZnO-based TFTs through spray pyrolysis processing. Plasma-enhanced chemical vapor deposition (PECVD).

\section{Results and Discussion}

Spray pyrolysis is a unique depositing method which can spray materials over a large area on a glass substrate. Bo-Xuan Yang et al. presented a transparent ZnO-based thin film transistors that were fabricated on a glass substrate with solution processes. The TFTs were indeed highly transparent (transmission of $\sim 70 \%$ in the visible spectrum) and showed excellent electrical characteristics including an $\mathrm{I}_{\mathrm{ON}} / \mathrm{I}_{\mathrm{OFF}}$ ratio of approximately $10^{4}$ through the spray pyrolysis to deposit the active $\mathrm{ZnO}$ channel layer. These results represent significant achievements toward low cost and low energy consumption transparent oxide TFTs based on simple solution-based processes [24,37]. However, the spray-deposited film still exhibited high roughness of the micro-grade film as compared with the spin-coated film, and a high temperature manufacturing process $>400{ }^{\circ} \mathrm{C}$ was involved.

Herein, we established a simple, low-temperature manufacturing (all processes were about $300{ }^{\circ} \mathrm{C}$ ) and novel structure of highly transparent ( $>75 \%$ in the visible-light region between 400 and $800 \mathrm{~nm}$ wavelength) of the ZnO-based TFTs with AuNPs heterojunction which were fabricated on a FTO structure for extending the light absorption wavelength during visible-light detection. These TCO materials can convert a UV wavelength region into an electrical signal. Moreover, the $\mathrm{ZnO}$ thin-film exhibited a markedly smoother channel layer with significantly lower surface roughness of $1.84 \mathrm{~nm}$ via the spray-deposited method, and superior electrical performance with higher electron mobility in a linear region and a higher $\mathrm{I}_{\mathrm{ON}}-\mathrm{I}_{\mathrm{OFF}}$ ratio of approximately $10^{5}$. These electrical characteristics are not only competitive compared to the previous reports but also compared to those of the $\mathrm{ZnO}$-based photo-detectors via spray pyrolysis. To validate the TFT photodetection ability and photosensitivity in this study, the morphology and typical transfer electrical characteristics of the TFT fabricated through 
spray deposition under various conditions were evaluated. Figure $2 \mathrm{a}-\mathrm{c}$ respectively present the cross-sectional images of spray deposition with one, two, and three layers of $0.05 \mathrm{M} \mathrm{ZnO}$ thin-film through post-annealing at $300{ }^{\circ} \mathrm{C}$. The semiconducting channel with $\mathrm{ZnO}$ thin film thickness of approximately $15.98,28.54$, and $58.90 \mathrm{~nm}$ were obtained through one, two, and three rounds of spray deposition, respectively. The thickness of the spray-deposited layer was approximately $15 \mathrm{~nm}$, and it linearly increased with the increasing number of sprays. This observation indicates that the spray deposition technique can provide a stable and large-scale approach for depositing a semiconducting $\mathrm{ZnO}$ channel layer that is inexpensive and is easy to handle for the fabrication of micro-electronics and large-scale film manufacturing. To evaluate the electrical characteristics of the ZnO-based TFTs with channel layers of different thickness, the drain-current ( $\mathrm{I}_{\mathrm{DS}}$ ) was first controlled before measuring the electrical properties of the devices by applying a back-gate bias voltage $\left(\mathrm{V}_{\mathrm{GS}}\right)$ to the FTO substrate used as a back-gate electrode. Figure $2 \mathrm{~d}$ shows the typical transfer characteristics of drain-source current versus gate voltage $\left(\mathrm{I}_{\mathrm{DS}}-\mathrm{V}_{\mathrm{GS}}\right.$ ) of the $\mathrm{ZnO}$-based TFTs with $\mathrm{ZnO}$ channel layers that have thicknesses of $15.98,28.54$, and $58.90 \mathrm{~nm}$, and which were operated by varying $\mathrm{V}_{\mathrm{GS}}$ from -20 to $30 \mathrm{~V}$ at a constant $\mathrm{V}_{\mathrm{DS}}$ of $5 \mathrm{~V}$ on a logarithmic scale. Both devices demonstrated saturation behaviors when $\mathrm{V}_{\mathrm{GS}}$ became more positive, and the devices' properties were switched on by the electrons accumulated in the n-type $\mathrm{ZnO}$ channel layer under a positive $\mathrm{V}_{\mathrm{GS}}$, which was applied by the back gate electrode of the FTO substrate. When the $\mathrm{V}_{\mathrm{GS}}$ was $30 \mathrm{~V}$, the on-off current $\left(\mathrm{I}_{\mathrm{ON}}-\mathrm{I}_{\mathrm{OFF}}\right)$ ratio was approximately $10^{3}$, and the device with a $\mathrm{ZnO}$ channel layer with a thickness of $58.90 \mathrm{~nm}$ exhibited an unsatisfactory $\mathrm{I}_{\mathrm{ON}}-\mathrm{I}_{\mathrm{OFF}}$ ratio of approximately $10^{1}$ because the thickness of the $\mathrm{ZnO}$ layer was too great for the $\mathrm{V}_{\mathrm{DS}}$ to be sufficient to turn on the channel properties.

(a)

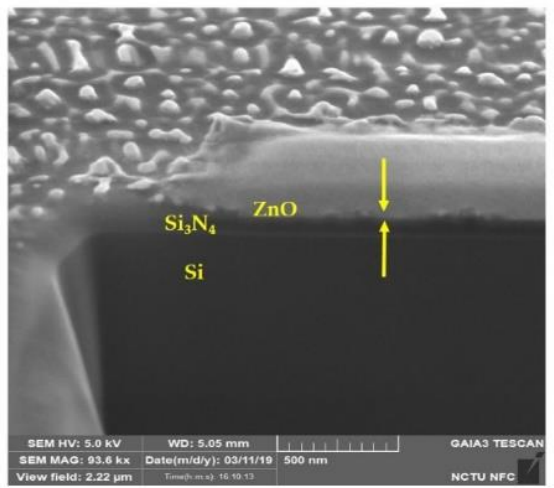

(c)

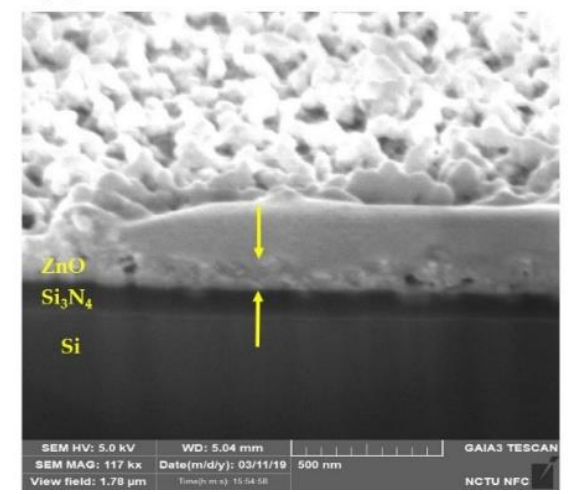

(b)

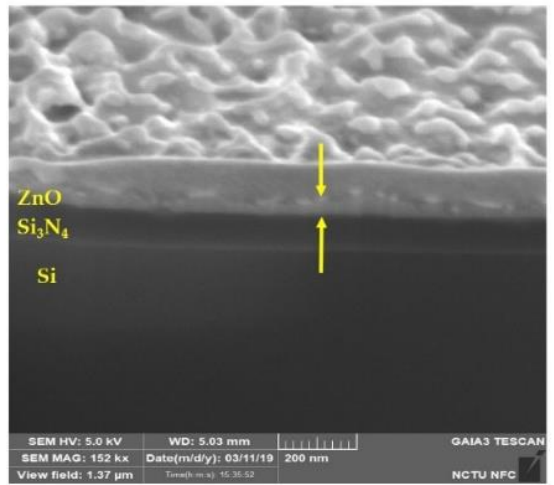

(d)

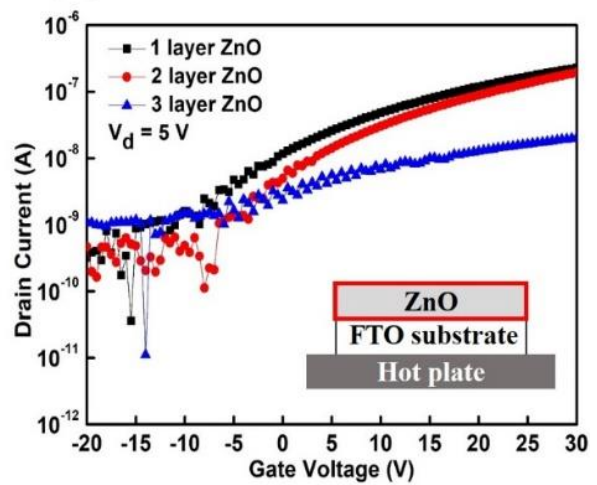

Figure 2. Focus ion beam cross-section images of the $\mathrm{ZnO}$-based TFTs with the $\mathrm{ZnO}$ channel layer sprayed (a) once, (b) twice, and (c) thrice; (d) typical transfer characteristics of drain-source current versus gate voltage $\left(\mathrm{I}_{\mathrm{DS}}-\mathrm{V}_{\mathrm{GS}}\right)$ of $\mathrm{ZnO}$-based TFTs with $\mathrm{ZnO}$ channel layers that have thicknesses of $15.98,28.54$, and $58.90 \mathrm{~nm}$. 
Furthermore, the roughness of the interaction between the spray nozzle and the substrate was investigated at different distances. Continuous $\mathrm{ZnO}$ channel layers were deposited through sequential, continual spray coatings with two runs (two spraying cycles); each spraying cycle lasted for 10 seconds. Figure 3 shows the effect of spray deposition at different distances on the surface topography of the $\mathrm{ZnO}$ thin film layer and TFT electrical performance. Figure $3 \mathrm{a}, \mathrm{b}$ respectively present the atomic force microscopy (AFM) images of the dried $\mathrm{ZnO}$ thin film patterns of individual spray-deposited layers on $\mathrm{Si} / \mathrm{Si}_{3} \mathrm{~N}_{4}$ substrates at the distances of 10 and $20 \mathrm{~cm}$. The results reveal that the average roughness of the $\mathrm{ZnO}$ thin film deposition at the distances of 10 and $20 \mathrm{~cm}$ between the nozzle and substrate were 11.0 and $1.84 \mathrm{~nm}$, respectively. The $\mathrm{ZnO}$ thin film morphology at the distance of $20 \mathrm{~cm}$ exhibited a significantly smoother channel layer with significantly lower surface roughness compare with the $\mathrm{ZnO}$ thin film at $10 \mathrm{~cm}$. This is a crucial observation because the increasing distance of the spray nozzle and substrate can suppress the impact of the valve pressure on the $\mathrm{ZnO}$ thin film, and a smoother semiconducting layer was created for the reliable electrical operation of electronic devices through spray pyrolysis deposition. Figure $3 c$ presents the typical transfer characteristics of drain-source current versus gate voltage $\left(\mathrm{I}_{\mathrm{DS}}-\mathrm{V}_{\mathrm{GS}}\right)$ for two layers of several semiconducting channel $\mathrm{ZnO}$ thin films deposited when the distance between the nozzle and substrate was $20 \mathrm{~cm}$. The aforementioned $\mathrm{ZnO}$ surface topography discussion indicates that TFTs with $\mathrm{ZnO}$ thin film spray-deposited at $20 \mathrm{~cm}$ exhibited a superior electrical performance with higher electron mobility in the linear region and a higher $\mathrm{I}_{\mathrm{ON}} \mathrm{I}_{\mathrm{OFF}}$ of approximately $10^{5}$. Furthermore, Figure $\mathrm{S} 1$ presents the 10 devices of typical transfer characteristics of drain-source current versus gate voltage $\left(\mathrm{I}_{\mathrm{DS}}-\mathrm{V}_{\mathrm{GS}}\right)$ and the square root of the drain current-gate voltage transfer characteristics curves, and our films exhibited superior stable electrical performance with a lower leakage current and higher electron mobility in the linear region. This clearly demonstrates the benefits of a spray-deposition $\mathrm{ZnO}$ channel film at a distance of $20 \mathrm{~cm}$.

(a)

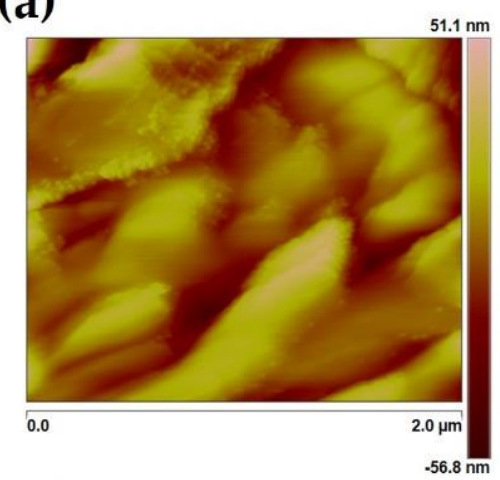

(b)

(c)
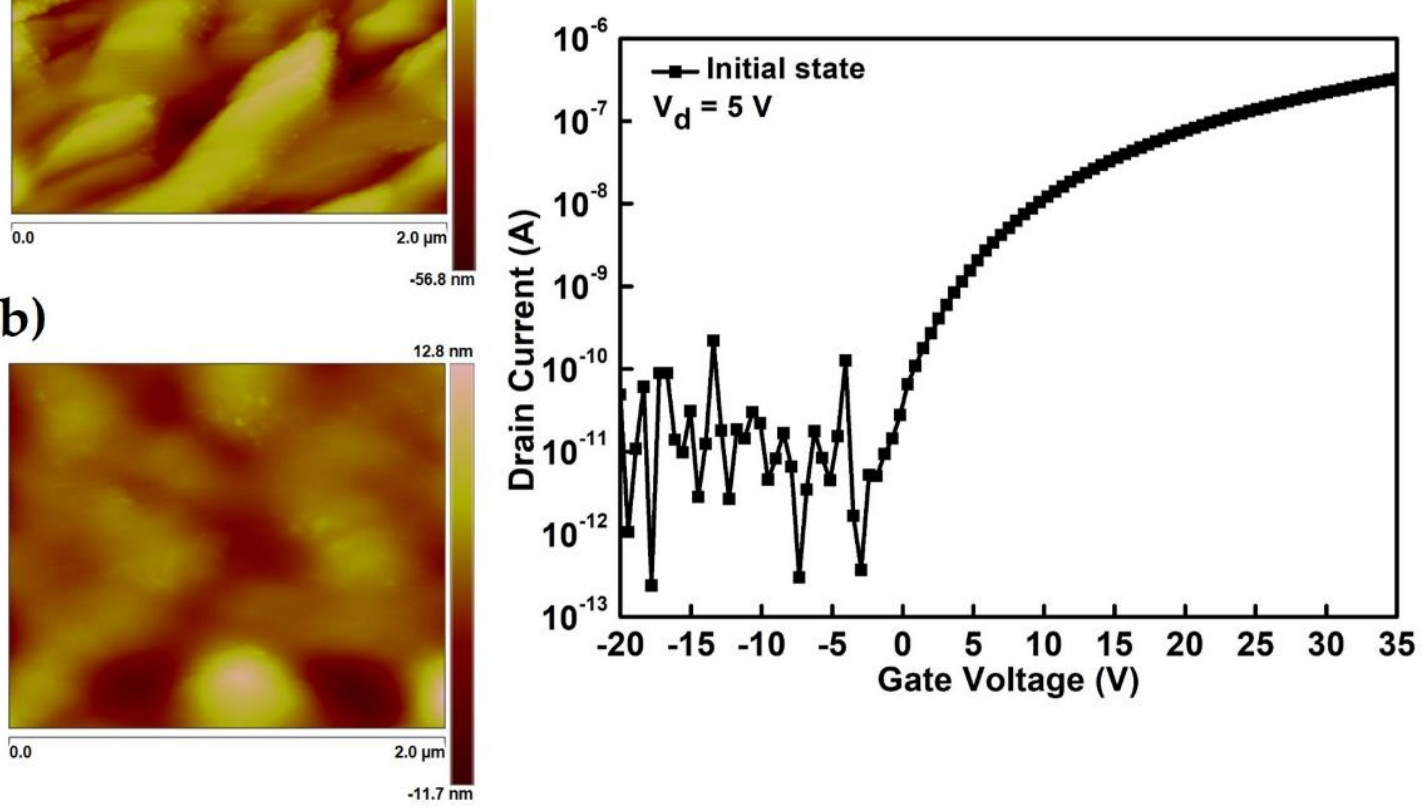

Figure 3. Atomic force microscopy images of the semiconducting channel $\mathrm{ZnO}$ thin film spray-deposited at the distances of (a) $10 \mathrm{~cm}$ and (b) $20 \mathrm{~cm}$ between the spray nozzle and substrate. (c) Transfer characteristics of drain-source current versus gate voltage $\left(\mathrm{I}_{\mathrm{DS}}-\mathrm{V}_{\mathrm{GS}}\right)$ of two layers of several semiconducting channel $\mathrm{ZnO}$ thin films deposited at a distance of $20 \mathrm{~cm}$ between the nozzle and substrate. 
The transparent photodetector with ZnO-based TFTs and AuNP structure was fabricated on a glass substrate of FTO, as shown in Figure 4a. The device exhibits outstanding transparency with high transmittance ( $>75 \%$ in the visible-light region between 400 and $800 \mathrm{~nm}$ wavelength). As seen in the inset image of Figure 4a, visible-light can penetrate our devices, and can penetrate an active channel consisting of a photosensitive region with $\mathrm{ZnO}$ and AuNPs of $20 \mathrm{~nm}$ thickness, where AuNPs were placed between the semiconducting channel $\mathrm{ZnO}$ and $\mathrm{Si}_{3} \mathrm{~N}_{4}$ gate dielectric with concentrations of $1.26,12.6$, and $126 \mathrm{pM}$, to validate the photosensitivity of an active $\mathrm{ZnO}$ thin film with different concentrations of AuNPs for visible-light illumination (under halogen lamp illumination). Figure S2 displays a scanning electron microscopy image of AuNPs distributed in the channel region of $\mathrm{ZnO}$ between the source and drain electrodes.
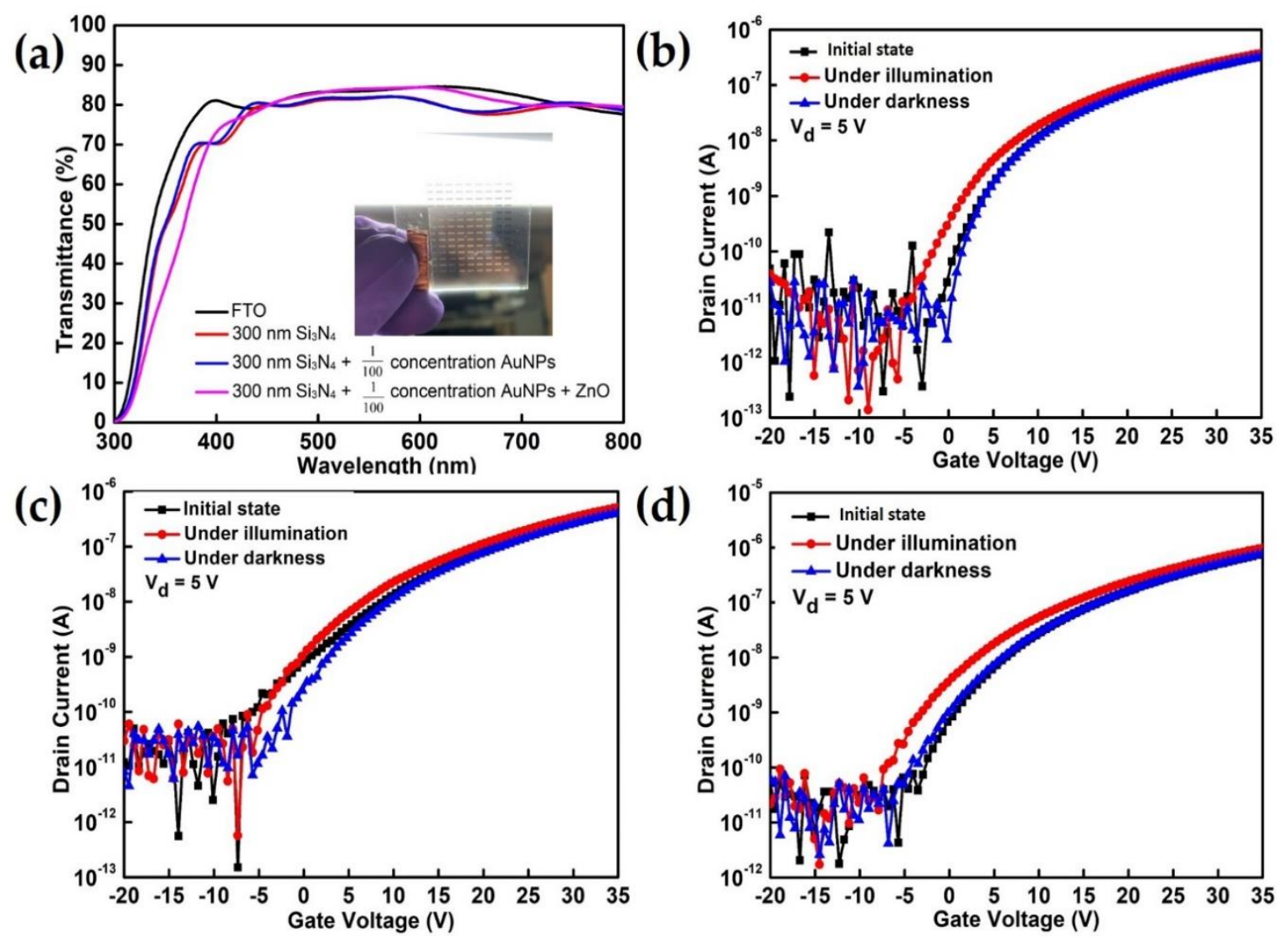

Figure 4. (a) Transmittance of the phototransistor based on $\mathrm{ZnO}$ and AuNPs on the transparent glass of an FTO substrate (inset image shows the optical photo on our devices). Typical transfer characteristics of the $\mathrm{ZnO} / \mathrm{AuNPs}$-based structure TFTs with and without visible-light illumination, where AuNPs were placed between the semiconducting channel $\mathrm{ZnO}$ and $\mathrm{Si}_{3} \mathrm{~N}_{4}$ gate dielectric with concentrations of (b) 1.26 , (c) 12.6 , and (d) 126 pM.

Recently, Hojoong Choi et al. have reported a solution-processed $\mathrm{ZnO} / \mathrm{SnO}_{2}$ bilayer ultraviolet photo-transistor device with a high responsivity of $\sim 82.28 \mathrm{~A} / \mathrm{W}$ and fast photo-response and recovery times of 5.39 and 4.37 seconds, respectively, under the wavelength of $365 \mathrm{~nm}$ UV illumination [8]. This is a perfect structure and approach for improving the performance of UV photo-transistors. However, the $\mathrm{ZnO}$ can convert only the UV wavelength region into an electrical signal because the intrinsically wide band-gap limits the light absorption of the high-energy UV region. In contrast, for both devices in this study, the on-current was significantly enhanced under visible light wavelength by the incorporation of AuNPs in the $\mathrm{ZnO}$ semiconducting channel layer, and the photo-current increased with the increasing AuNP concentrations when the amplification interval of the saturation region of the on-current between the gate voltage of 30-35 V, as indicated in Figure S3. The typical transfer 
$\mathrm{I}_{\mathrm{DS}}-\mathrm{V}_{\mathrm{GS}}$ characteristics of the initial state of the devices, with and without visible-light illumination, are presented in Figure $4 \mathrm{~b}-\mathrm{d}$. Photo-transistors demonstrated increased on-current values reaching $3.75,5.18$, and $9.79 \times 10^{-7} \mathrm{~A}$, with applied gate and drain voltages with increasing AuNP density and concentrations of $1.26,12.6$, and $126 \mathrm{pM}$. As mentioned, plasmonic energy absorption generates hot electrons in gold NPs and these hot electrons can migrate across the ZnO-AuNPs heterojunction and diffuse in the active $\mathrm{ZnO}$ film with a specific light wavelength, thereby increasing the saturation current of devices. Several methods have been reported to improve the photo-responsivity of TCO-based TFTs in a visible wavelength region, such as the use of quantum dots, and polymeric absorption thin-film layers [12-14]. However, the nanostructure arrangement within large-area uniformity of quantum dots, and polymeric absorption layers are a critical issue, and the rough film will create poor electrical characteristics. Those material's sensitivity to visible light wavelengths are still quite low. Compared to the previous reports, we achieved a large-area uniformity of $\mathrm{ZnO}$ and Au-NPs heterojunction nanohybrid structure (roughness $\sim 1.8 \mathrm{~nm}$ ) of photodetectors, that not only amplifies the photo-current but also efficient conversion of plasmon energy into an electrical signal for an illumination-specific light wavelength. As expected, the threshold voltage $\left(\mathrm{V}_{\text {th }}\right)$ also drifts to considerably more negative values with increasing AuNP density. Figure S1 presents the square root of the drain current-gate voltage transfer characteristics curves of the initial state of the devices, under illumination and with eliminated light illumination. The $\Delta \mathrm{V}_{\text {th }}$ were the values 2.6, 3.1, and $3.6 \mathrm{~V}$, which corresponded to the concentrations of $1.26,12.6$, and $126 \mathrm{pM}$, respectively, under the visible light illumination. In all devices, the electrical parameters of the TFT device were affected by the increasing on-current, and $\Delta \mathrm{Vth}$ values became increasingly negative when the AuNPs- $\mathrm{ZnO}$ (metal-semiconductor) heterojunction nanohybrids structure was subject to visible to visible-light illumination without any accompanying field-effect mobility $\left(\mu_{\mathrm{FE}}\right)$ degradation. The Vth drift into negative values was attributed to the corresponding visible-light wavelength of AuNPs, as well as photo-induced free carriers, which can be vigorously activated in $\mathrm{ZnO}$ films, in which localized surface plasmon energy has induced electron-hole pairs in the $\mathrm{ZnO}$ film. The electrical characteristics recovered their initial states after the visible-light illumination was turned off. These results indicate that highly transparent phototransistors based on $\mathrm{ZnO}$ TFTs with an AuNP structure that are highly photo-sensitive to visible-light wavelength can be fabricated using transparent, conductive oxide materials and metallic nanoparticles with a wide bandgap material.

The extension of the light absorbed during visible-light photodetection is obtained through the amplification of plasmon detection and Figure 5 depicts the working principle. A metal-semiconducting junction structure can convert plasmonic energy into an electrical signal and increase the current with a specific visible light wavelength. In this study, the nanoparticles with a diameter of $13 \mathrm{~nm}$ exhibited strong plasmonic absorption at light wavelengths of 495-570 nm (green light). Photons absorbed in the metallic particles of a nanostructure that generates hot electrons in junctions in the semiconducting channel layer, thereby generating photo-current (saturation current increasing) and modifying the energy band, in semiconducting $\mathrm{ZnO}$ channel properties (Vth drift to negative values). The ZnO-based TFTs collects plasmonically induced hot electrons from the AuNPs, and these hot electrons can migrate across the $\mathrm{ZnO}-\mathrm{AuNPs}$ heterojunction and diffuse in the active semiconducting channel of $\mathrm{ZnO}$ film with a specific light wavelength of $495-570 \mathrm{~nm}$, thereby increasing the saturation current. Moreover, the photo-transistors demonstrated increased on-current with applied gate and drain voltages accompanied by the increasing AuNP density and concentrations of 1.26, 12.6, and $126 \mathrm{pM}$. Furthermore, the threshold voltage (Vth) also drifted to considerably more negative values with increasing AuNPs density. This was attributed to the corresponding visible-light wavelength of AuNPs, as well as photo-induced free carriers, which can be vigorously activated in a $\mathrm{ZnO}$ film, in which localized surface plasmon energy has induced electron-hole pairs in the $\mathrm{ZnO}$ film. Therefore, the $\mathrm{ZnO} / \mathrm{AuNPs}$-based TFTs converted localized surface plasmon energy into an electrical signal, thus extending the wide band gap of the material used in the photodetector to enable visible-light wavelength detection. 


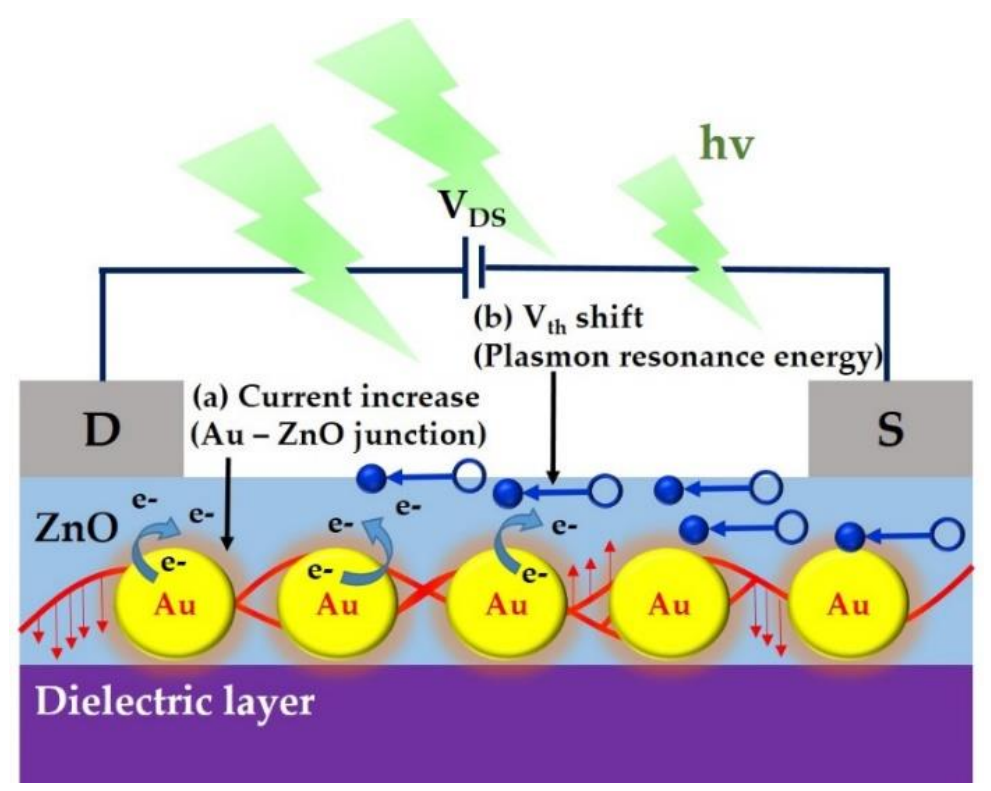

Figure 5. Mechanism of visible-light induced photocurrent and energy-band modification on the hybrid junction of metallic AuNPs and semiconducting $\mathrm{ZnO}$ film.

\section{Conclusions}

In summary, highly transparent ZnO-based TFTs with AuNPs were fabricated on a FTO structure, for extending the light absorption wavelength during visible-light detection through the solution-based processing of spray pyrolysis, and a thickness dependent experiment was performed on the $\mathrm{ZnO}$ films. The thickness of the deposited spray was approximately $15 \mathrm{~nm}$, and it increased linearly with the increasing number of sprays. This observation indicates that the spray deposition technique can provide a stable approach for large-scale deposition of semiconducting $\mathrm{ZnO}$ channel layers. Furthermore, a comparison of the roughness of $\mathrm{ZnO}$ thin films deposited at distances of 10 and $20 \mathrm{~cm}$ between the nozzle and substrate revealed that the distance of $20 \mathrm{~cm}$ for deposition produced a significantly smoother channel layer on the $\mathrm{ZnO}$ thin film with lower surface roughness compared with deposition at the distance of $10 \mathrm{~cm}$. Finally, a visible-light photodetector was fabricated using a hybrid active channel material based on $\mathrm{ZnO}$ film and AuNPs. A wide-bandgap $\mathrm{ZnO}$ film was used as a transparent semiconducting channel layer, and metallic AuNPs were adopted to absorb and induce photocurrent and energy-band modifications under visible-light illumination. A metal-semiconducting junction structure can convert plasmonic energy into an electrical signal and increase the current under a specific visible-light wavelength. Therefore, the results indicate that highly transparent phototransistors based on ZnO TFTs AuNP structures that are highly sensitive to visible-light can be fabricated using TCO materials and metallic nano-particles with wide-bandgaps.

Supplementary Materials: The following are available online at http://www.mdpi.com/1996-1944/12/21/3639/s1, Figure S1: (a) Transfer characteristics of drain-source current versus gate voltage (IDS-VGS) of 10 devices of several semiconducting channel $\mathrm{ZnO}$ thin films deposited at a distance of $20 \mathrm{~cm}$ between the nozzle and substrate. (b) The square root of the drain current-gate voltage transfer characteristics curves of the 10 devices, Figure S2: The Scanning electron microscopy (SEM) image of the gold NPs under the ZnO thin-film. The scale bar in the SEM image is $100 \mathrm{~nm}$, Figure S3: The typical transfer IDS-VGS characteristics of amplification intervals for the saturation region of the on-current between gate voltage operation at 30-35 volts, and the devices with AuNPs concentration of (a) 1.26, (b) 12.6, and (c) $126 \mathrm{pM}$. The square root of the drain current-gate voltage transfer characteristics curves of the devices with initial state, under illumination and without light illumination, the $\Delta$ Vth were 2.6, 3.1, and 3.6 volts which corresponded to the concentrations of (d) 1.26, (e) 12.6, and (f) 126 pM, respectively.

Author Contributions: C.-J.W., H.-C.Y., and F.-H.K. conceived and designed the experiments; C.-J.W., K.L., J.-H.O., and K.-H.C. performed the experiments and analyzed the data; C.-J.W. wrote the paper, while all authors contributed with corrections and figures. 
Funding: This research was funded by Ministry of Science and Technology of Taiwan with grant number MOST 106-2113-M-009-015-MY3 and MOST 108-2218-E-007-039.

Conflicts of Interest: The authors declare no conflict of interest.

\section{References}

1. Ahn, B.D.; Jeon, H.J.; Sheng, J.; Park, J.; Park, J.S. A review on the recent developments of solution processes for oxide thin film transistors. Semicond. Sci. Technol. 2015, 30, 064001. [CrossRef]

2. Song, K.; Noh, J.; Jun, T.; Jung, Y.; Kang, H.Y.; Moon, J. Fully flexible solution-deposited ZnO thin-film transistors. Adv. Mater. 2010, 22, 4308-4312. [CrossRef] [PubMed]

3. Xu, W.; Li, H.; Xu, J.B.; Wang, L. Recent Advances of Solution-Processed Metal Oxide Thin-Film Transistors. ACS Appl. Mater. Interfaces 2018, 10, acsami.7b16010. [CrossRef]

4. Nam, S.; Yang, J.H.; Cho, S.H.; Choi, J.H.; Kwon, O.S.; Park, E.S.; Lee, S.J.; Cho, K.I.; Jang, J.; Hwang, C.S. Solution-processed indium-free $\mathrm{ZnO} / \mathrm{SnO}_{2}$ bilayer heterostructures as a low-temperature route to high-performance metal oxide thin-film transistors with excellent stabilities. J. Mater. Chem. C 2016, 4, 11298-11304. [CrossRef]

5. Liu, X.; Wang, J.; Liao, C.; Xiao, X.; Guo, S.; Jiang, C.; Fan, Z.; Wang, T.; Chen, X.; Lu, W.; et al. Transparent, high-performance thin-film transistors with an $\mathrm{InGaZnO}_{\text {Aligned-SnO}}$-nanowire composite and their application in photodetectors. Adv. Mater. 2014, 26, 7399-7404. [CrossRef] [PubMed]

6. Ahn, C.H.; Kang, W.J.; Kim, Y.K.; Yun, M.G.; Cho, H.K. Highly Repeatable and Recoverable Phototransistors Based on Multifunctional Channels of Photoactive CdS, Fast Charge Transporting ZnO, and Chemically Durable $\mathrm{Al}_{2} \mathrm{O}_{3}$ Layers. ACS Appl. Mater. Interfaces 2016, 22, 15518-15523. [CrossRef] [PubMed]

7. Yu, J.; Javaid, K.; Liang, L.; Wu, W.; Liang, Y.; Song, A.; Zhang, H.; Shi, W.; Chang, T.C.; Cao, H. High-Performance Visible-Blind Ultraviolet Photodetector Based on IGZO TFT Coupled with p-n Heterojunction. ACS Appl. Mater. Interfaces 2018, 10, 8102-8109. [CrossRef] [PubMed]

8. Choi, H.; Seo, S.; Lee, J.H.; Hong, S.H.; Song, J.; Kim, S.; Yim, S.Y.; Lee, K.; Park, S.J.; Lee, S. Solution-processed $\mathrm{ZnO} / \mathrm{SnO} 2$ bilayer ultraviolet phototransistor with high responsivity and fast photoresponse. J. Mater. Chem. C 2018, 6, 6014-6022. [CrossRef]

9. Thepnurat, M.; Chairuangsri, T.; Hongsith, N.; Ruankham, P.; Choopun, S. Realization of Interlinked ZnO Tetrapod Networks for UV Sensor and Room-Temperature Gas Sensor. ACS Appl. Mater. Interfaces 2015, 7, 24117-24184. [CrossRef] [PubMed]

10. Cao, F.; Tian, W.; Gu, B.; Ma, Y.; Lu, H.; Li, L. High-performance UV-vis photodetectors based on electrospun ZnO nanofiber-solution processed perovskite hybrid structures. Nano Res. 2017, 10, 2244-2256. [CrossRef]

11. Liu, X.; Gu, L.; Zhang, Q.; Wu, J.; Long, Y.; Fan, Z. All-printable band-edge modulated ZnO nanowire photodetectors with ultra-high detectivity. Nat. Commun. 2014, 5, 1-9. [CrossRef] [PubMed]

12. Gong, M.; Liu, Q.; Cook, B.; Kattel, B.; Wang, T.; Chan, W.L.; Ewing, D.; Casper, M.; Stramel, A.; Wu, J.Z. All-Printable ZnO Quantum Dots/Graphene van der Waals Heterostructures for Ultrasensitive Detection of Ultraviolet Light. ACS Nano 2017, 11, 4114-4123. [CrossRef] [PubMed]

13. Jing, W.; Ding, N.; Li, L.; Jiang, F.; Xiong, X.; Liu, N.; Zhai, T.; Gao, Y. Ag nanoparticles modified large area monolayer MoS_2 phototransistors with high responsivity. Opt. Express 2017, 25, 14565. [CrossRef] [PubMed]

14. Shin, S.W.; Lee, K.H.; Park, J.S.; Kang, S.J. Highly Transparent, Visible-Light Photodetector Based on Oxide Semiconductors and Quantum Dots. ACS Appl. Mater. Interfaces 2015, 7, 19666-19671. [CrossRef] [PubMed]

15. Wu, Z.Q.; Yang, J.L.; Manjunath, N.K.; Zhang, Y.J.; Feng, S.R.; Lu, Y.H.; Wu, J.H.; Zhao, W.W.; Qiu, C.Y.; Li, J.F.; et al. Gap-Mode Surface-Plasmon-Enhanced Photoluminescence and Photoresponse of $\mathrm{MoS}_{2}$. Adv. Mater. 2018, 30, 1-7. [CrossRef] [PubMed]

16. Li, Z.; Xiao, Y.; Gong, Y.; Wang, Z.; Kang, Y.; Zu, S.; Ajayan, P.M.; Nordlander, P.; Fang, Z. Active Light Control of the MoS2 Monolayer Exciton Binding Energy. ACS Nano 2015, 9, 10158-10164. [CrossRef] [PubMed]

17. Wu, K.; Rodríguez-Córdoba, W.E.; Yang, Y.; Lian, T. Plasmon-induced hot electron transfer from the Au tip to CdS rod in CdS-Au nanoheterostructures. Nano Lett. 2013, 13, 5255-5263. [CrossRef]

18. Yang, Z.; Liu, M.; Liang, S.; Zhang, W.; Mei, T.; Zhang, D.; Chua, S.J. Hybrid modes in plasmonic cavity array for enhanced hot-electron photodetection. Opt. Express 2017, 25, 20268. [CrossRef] 
19. Kojori, H.S.; Yun, J.H.; Paik, Y.; Kim, J.; Anderson, W.A.; Kim, S.J. Plasmon Field Effect Transistor for Plasmon to Electric Conversion and Amplification. Nano Lett. 2016, 16, 250-254. [CrossRef]

20. Kim, J.; Park, C.J.; Yi, G.; Choi, M.S.; Park, S.K. Low-temperature solution-processed gate dielectrics for high-performance organic thin film transistors. Materials 2015, 8, 6926-6934. [CrossRef]

21. Cai, W.; Zhu, Z.; Wei, J.; Fang, Z.; Ning, H.; Zheng, Z.; Zhou, S.; Yao, R.; Peng, J.; Lu, X. A simple method for high-performance, solution-processed, amorphous $\mathrm{ZrO}_{2}$ gate insulator TFT with a high concentration precursor. Materials 2017, 10, 972. [CrossRef] [PubMed]

22. Qin, Y.; Su, J.; Wan, L.; He, F.; Hao, Y.; Lin, Z.; Chang, J. Effects of Interfacial Passivation on the Electrical Performance, Stability, and Contact Properties of Solution Process Based ZnO Thin Film Transistors. Materials 2018, 11, 1761.

23. Ji, S.Y.; Choi, W.; Kim, H.Y.; Jeon, J.W.; Cho, S.H.; Chang, W.S. Fully solution-processable fabrication of multi-layered circuits on a flexible substrate using laser processing. Materials 2018, 11, 268. [CrossRef] [PubMed]

24. Wang, C.J.; You, H.C.; Ko, F.H. The highly electrical performances of flexible indium-zinc-oxide based thin-film transistors on stability improvement by passivation layer. Microelectron. Eng. 2017, 177, 87-92. [CrossRef]

25. You, H.C.; Wang, C.J. Low-temperature, solution-processed, transparent zinc oxide-based thin-film transistors for sensing various solvents. Materials 2017, 10, 234. [CrossRef]

26. Ning, H.; Chen, J.; Fang, Z.; Tao, R.; Cai, W.; Yao, R.; Hu, S.; Zhu, Z.; Zhou, Y.; Yang, C.; et al. Direct inkjet printing of silver source/drain electrodes on an amorphous InGaZnO layer for thin-film transistors. Materials 2017, 10, 51. [CrossRef]

27. Lee, H.; Zhang, X.; Hwang, J.; Park, J. Morphological influence of solution-processed zinc oxide films on electrical characteristics of thin-film transistors. Materials 2016, 9, 851.

28. Rao, M.G.S.; Sánchez-Martinez, A.; Gutiérrez-Heredia, G.; Quevedo-López, M.A.; Ramírez-Bon, R. Sol-gel derived low temperature $\mathrm{HfO}_{2}$-GPTMS hybrid gate dielectric for a-IGZO thin-film transistors (TFTs). Ceram. Int. 2018, 44, 16428-16434. [CrossRef]

29. Ozden, B.; Sk, M.H.; Park, M.; Khanal, M.P.; Sultan, M.S.; Hamilton, M.C.; Ahyi, A.C.; Yapabandara, K.; Uprety, S.; Wang, S.; et al. On the anomaly in the electrical characteristics of thin film transistors with multi-layered sol-gel processed ZnO. Thin Solid Films 2019, 672, 152-156.

30. Kwon, Y.J.; Park, Y.D.; Lee, W.H. Inkjet-printed organic transistors based on organic semiconductor/insulating polymer blends. Materials 2016, 9, 650. [CrossRef]

31. Zeumault, A.; Scheideler, W.; Subramanian, V. Electrostatic Tuning of Spray-Deposited ZnO for Controlled Mobility Enhancement. Adv. Funct. Mater. 2017, 27, 1-10. [CrossRef]

32. Sayed, M.H.; Robert, E.V.C.; Dale, P.J.; Gütay, L. $\mathrm{Cu}_{2} \mathrm{SnS}_{3}$ based thin film solar cells from chemical spray pyrolysis. Thin Solid Films 2019, 669, 436-439. [CrossRef]

33. Naveena, D.; Logu, T.; Dhanabal, R.; Sethuraman, K.; Bose, A.C. Comparative study of effective photoabsorber $\mathrm{CuO}$ thin films prepared via different precursors using chemical spray pyrolysis for solar cell application. J. Mater. Sci. Mater. Electron. 2019, 30, 561-572. [CrossRef]

34. Isakov, I.; Faber, H.; Grell, M.; Wyatt-Moon, G.; Pliatsikas, N.; Kehagias, T.; Dimitrakopulos, G.P.; Patsalas, P.P.; Li, R.; Anthopoulos, T.D. Exploring the Leidenfrost Effect for the Deposition of High-Quality $\operatorname{In}_{2} \mathrm{O}_{3}$ Layers via Spray Pyrolysis at Low Temperatures and Their Application in High Electron Mobility Transistors. Adv. Funct. Mater. 2017, 27, 1-9. [CrossRef]

35. Liu, H.Y.; Hung, C.C.; Hsu, W.C. Deposition of Oxide Thin Films by Ultrasonic Spray Pyrolysis Deposition for InGaZnO Thin-Film Transistor Applications. IEEE Electron Device Lett. 2018, 39, 1520-1523.

36. Mostafa, N.Y.; Badawi, A.; Ahmed, S.I. Influence of $\mathrm{Cu}$ and Ag doping on structure and optical properties of In2O3thin film prepared by spray pyrolysis. Results Phys. 2018, 10, 126-131. [CrossRef]

37. Yang, B.X.; Chien, Y.H.C.; Chang, T.; Liao, C.H.; Liu, C.Y.; Chiang, A.S.T.; Liu, C.L. Fully Solution-Processed Low-Voltage Driven Transparent Oxide Thin Film Transistors. Status Solidi A Appl. Mater. 2018, 215, 1800192. [CrossRef]

(C) 2019 by the authors. Licensee MDPI, Basel, Switzerland. This article is an open access article distributed under the terms and conditions of the Creative Commons Attribution (CC BY) license (http://creativecommons.org/licenses/by/4.0/). 